\section{Questión}

Periodismo / Comunicación ISSN 1669-6581
- Av. $44 \mathrm{~N}^{\circ} 676,1^{\circ}$ piso

CP 1900 - La Plata - Argentina

(4) www.perio.unlp.edu.ar/question

Lo que ayudó a visibilizar la pandemia

Gustavo Melfi

DOI: https://doi.org/10.24215/16696581e339

\title{
Lo que ayudó a visibilizar la pandemia
}

\section{What helped make the pandemic visible}

\author{
Palabras Clave \\ Educación - Pandemia - Mercantilización - Derechos
}

Key Words

Education - Pandemic - Mercantilization - Rights

"LA PANDEMIA ESTÁ EN NOSOTROS", eso fue lo único que escuche cuando me despedía de la almacenera de la vuelta de casa, y no fueron palabras de ella, sino del hombre que estaba detrás de mí, a un metro y medio de distancia como dicen los especialistas. Eso, no escuche nada más y me fui.

Sinceramente no repare en la palabra, en ese momento, pensaba simplemente en no olvidarme nada porque no había anotado las cosas y el problema era volver a salir, que no podía volver a salir, en casa las compras se hacen una vez al día o cada dos días, según lo que haga falta, y es un ritual insoportable cada regreso de la calle, desde el calzado que pasa por un trapo con lavandina para sacar todo de las suelas, hasta el lavado de manos profundo, la bolsa de los mandados va directo a un costado de la entrada para luego sacar los productos 
y pasarlos por un trapo con lavandina, las frutas llevan la peor parte, es aún más cuidadoso el proceso y así cada cosa con el mayor de los cuidados, como nos indican los especialistas, y nos bombardean por todos lados.

En todo eso pensaba mientras despedía a la almacenera y avanzaba ese hombre detrás de mí, se paró frente a la ventanilla externa, provisoria, y tiró esa frase mientras me alejaba, pero no le di mayor importancia.

Muchas horas después, en la soledad de la tarde mientras preparaba el mate, comencé a pensar en la frase de ese hombre, no lo había registrado en ese instante pero volvió a mí en una conversación con Laura, tratando de analizar y mirar en perspectiva todo aquello que nos estaba/está atravesando y que nos tiene como protagonistas, a nosotros a nuestras familias, los amigos, la ciudad entera, el país y gran parte del mundo, un caso inédito y mundial...sí, mucha tela para cortar sobre el COVID-19.

Existen permisos raros que nos damos a veces los periodistas, los comunicadores, pensando siempre en la oportunidad de buscar una gran historia o crearla cuando no la hay, de materializar los procesos-sucesos comunicacionales, pero acá la cosa era distinta, había historia, existía-existe y se reabre una nueva, distinta a cada instante, en cada casa, por donde miremos, ahí, hay algo para contar, para decir y están a nuestra disposición, comenzar a ordenar y organizar todo eso, es el nuevo desafío.

Vuelvo, decía que comencé a pensar en nuestra/s realidades, y vinieron cosas locas pero reales a mi cabeza, hoy más reales que nunca, pensar en la posibilidad concreta de observar un mundo totalmente paralizado, (con los reparos y características particulares de cada país, de cada ciudad), paralizados por un VIRUS, que no nos permite salir de nuestras casas, "ni en la mejor de las ficciones". Lo más increíble de todo esto es que es real, es muy real, y que todo es parte de un relato, que hace más de 30 días, se convirtió en cotidianeidad/realidad.

Entonces comenzaron a cruzarse pensamientos, a rever prácticas que no hubiéramos pensado nunca en aplicar o poner en discusión, a pensar en el ámbito laboral, como resolver ciertas cosas y todo lo que cambia la distancia. Ahí entra en juego el rol docente, inevitablemente muchos nos sentimos atravesados por esta realidad y el nuevo rol que comenzamos a ocupar, los nuevos sentidos de la profesión y lo raro de esa frase que no tenía mucho que ver, pero nos lleva por aquí. 
El contexto y la Educación, y a eso sumado la Distancia", un fenómeno que muchos docentes salimos a abrazar rápidamente para no dejar a nuestros estudiantes sin nada, solos, lo digo desde el esfuerzo, el desafío, pero por sobre todo, desde el compromiso docente. Sumado por otro lado, la prudente decisión política del Estado, de acompañar y regular estos procesos garantizando el derecho a la Educación en todos sus niveles, pero también algunos otros derechos, que comenzamos a vislumbrar a medida que esto avanza.

Es notorio en medio de esta locura, y es una locura, no hace falta reparar mucho en los sinónimos para describir la situación vivida y experimentada por todos/as, y se hace arduo el trabajo docentes, que comienzan el día pensando si van a poder entablar algún tipo de dialogo o contacto con sus estudiantes, pensando en el estudio, en cumplir con los programas, en ajustar y modificar planificaciones, en dar continuidad a los procesos educativos desde las herramientas que hay y tenemos a disposición todos nosotros, docentes y estudiantes, pensando siempre en acompañar, en estar, y en seguir transitando de la mejor forma posible esos saberes.

$Y$ digo estos saberes, porque como bien dice Boaventura de Sousa Santos, esos saberes que desconocemos, que son propiedad de otros contextos socioculturales, saberes internos y externos, lo que él denomina la Ecología de Saberes. Bueno, esos saberes internos, son con los que no queremos que dejen de contar nuestros estudiantes y decidimos acompañar este momento.

Inconscientemente y quizás también inevitablemente, toda esta situación del COVID-19, origen de la pandemia que estamos atravesando en Argentina y el Mundo entero, vino para quedarse y permitirnos realizar planteos que de otra forma no hubieran existido, o si, pero lo cierto, lo que está claro es que esta irrupción abrupta en la realidad de cada individuo y en las diversas sociedades, permiten pensarnos y repensar algunos conceptos / prácticas / desafíos / cuidados / jerarquización, y tanto más, que de otra manera hubieran sido procesos infinitos, larguísimos y siempre dependiendo del contexto, de los tiempos, la predisposición e intereses de algunos sectores para poder coincidir y discutir ciertos temas.

EI COVID-19 nos tomó por sorpresa y aceleró estas discusiones, las puso de manifiesto sobre la mesa, mostró las cartas y a mi consideración, también resalto el rol de algunos actores y sectores importantísimos y descuidados en los últimos tiempos dentro de la sociedad entre 
ellos "La Educación y La Salud", como así también la importancia del rol del Estado, como regulador y garante de derechos.

Predisponerme a escribir sobre la situación actual me lleva a pensar en las prácticas habituales, cotidianas, en la experiencia, a reflexionar sobre lo dicho anteriormente en relación a repensarnos como individuos y sociedad, a entender que inevitablemente se van a abrir nuevos caminos, nuevas voces y formas de hacer, (es lo que espero), pero por sobre todo me inquieta, me altera y me estimula pensar en las practicas docentes y los nuevos desafíos para este contexto. $Y$ no es por ser un especialista en el tema 0 un teórico, sino porque me es imposible separarme de la realidad que me constituye como sujeto, como docente, como comunicador y me atraviesa pensarme en esas prácticas, como a tantos otros/as supongo.

Aquí comienza el conflicto o mejor dicho el desafío, comenzar a ver esas prácticas tradicionales educativas que llevábamos adelante y que hoy no es de la misma manera, no son iguales, ni siquiera similares, pensado desde la predisposición y preparación tanto del docente como del estudiante para trasladarse y encontrarse en el aula, pasando por la relación y el vínculo cotidiano por un contacto visual, gestual o la discusión enriquecedora que siempre se puede dar o provocar en el aula, después de alguna intervención.

Podemos ver este momento como una oportunidad o que pase y ya, y sea parte de un recuerdo del pasado, un virus que vino a paralizar el mundo, nuestras vidas y listo. En este momento sugiero pensar en desafíos, en algunos conceptos que ponen de manifiesto la práctica docente, y a través de ella, el vínculo social, algunos intereses y recursos.

Me refiero a hacer un análisis sobre la situación actual, que este momento histórico nos permite y pone de manifiesto, "La Educación" es el punto de partida y para ello voy a comenzar con algunas afirmaciones para obviar discusiones viejas y de otros contextos políticos. Es conocido el trabajo y dedicación de los/as docentes en todos sus niveles y modalidades, de los equipos técnicos, de formación, y de "gestión", este último vale para aquellos que conocen y sienten la responsabilidad del lugar que ocupan. Dicho esto, hay algunos puntos que debemos observar con mayor atención, en estos momentos hay mucha información, en diarios, revistas y redes sociales sobre todo, todos hablamos de la labor, o el rol docente, si se debe dar continuidad al aprendizaje, si a la distancia es lo mismo, si se cumplen los objetivos y contenidos pedagógicos, evaluación y demás. 
Propongo por un momento sacar la vista de ese lugar y poner el foco de atención del otro lado. En los desafíos, en lo que no le permite al docente llegar a su objetivo, y lo mantienen alerta, en la desigualdad que siempre estuvo ahí y ahora podemos sacarla a la luz con más fuerza y argumentos, en lo que me gustaría llamar en este momento, como los factores que se convierten en "los enemigos de los docentes".

Podemos hacer una lista enorme de enemigos de los docentes, que son también enemigos de la sociedad, pero vamos a centrarnos en la educación y los docentes con estos desafíos, solo por nombrar algunos y darle sentido a este cambio de foco, de objetivo y enemigo, sacar el eje del rol y del desafío docente como algo propio, personal,(que no quiere decir que no existan), pero vamos a ponerlo en los desafíos externos, esos que no permiten llegar/hacer/cumplir, que no dejan de ser también deudas viejas.

Concretamente, entendiendo como Enemigo de los docentes, o enemigos que hacen que ese rol sea más difícil aún en este contexto particular y queda de manifiesto ante las dificultades visibles que atravesamos, hablamos de la Conectividad, el Acceso y el Contexto. Tres características-factores, que se relacionan entre sí, y que hoy imposibilitan que algunos sectores sociales, puedan hacer uso del derecho a la Educación Básica y obligatoria que involucra a los tres niveles educativos, Inicial, Primaria y Secundaria. (Ley de Educación Nacional N²6.206 - Año 2006). Pasa lo mismo con la Educación Superior Universitaria, con la salvedad que no involucra la obligatoriedad pero si, la libertad individual de poder elegir. (Declaración de la Conferencia Regional de la Educación Superior en América Latina y el Caribe-CRES 2008). Que expone que la Educación Superior es un Derecho Humano y un bien Público Social.

Estos desafíos implican poner en evidencia, las tres características-factores, de los que hablamos, la Conectividad, el Acceso y el Contexto, en relación a la conectividad podemos decir que dependemos pura y exclusivamente de mercados privados-abonados, con el monopolio de la comunicación y restringe económicamente a aquellos que no pueden acceder o contratar los mismos. El acceso, queda de esa forma supeditado a lo económico, a poder contar con recursos materiales-tecnológicos, para poder trabajar y realizar las prácticas desde los hogares, en este caso podemos decir que la mayoría de las personas cuentan con algún dispositivo tecnológico, pero eso no garantiza el acceso y que los mismos cuenten con los programas correspondientes para dicha finalidad. Finalmente el contexto es parte indiscutible 
de esta triada, conocer los diversos contextos, para trabajar es fundamental y forman parte de la desigualdad social que no solo nuestro país sufre, sino el mundo entero.

Comenzar a pensar, trabajar y elaborar proyectos desde el Estado, que contemplen estas dificultades, podrían ahorrarnos tiempo, años de discusiones, y estaríamos así, achicando la brecha de las desigualdades históricas, sociales, económicas y culturales, un estado presente, con políticas de integración coordinadas directamente con esos sectores que hoy son desprovistos de estos Derechos podría ser una salida. Es una discusión vieja tanto como la pobreza, pero quizá el contexto que tanto ha ayudado a entender y poner de un lado a los Especuladores y por otro al Estado, puede tomar fuerza para avanzar sobre políticas regulatorias, que en otro momento hubieran sido impensadas. Aunque quizás aún lo son todavía.

Hay dos ideas que derivan de este análisis y no quiero dejar de mencionar, porque sería fácil caer en ellas, por un lado es sabido que la educación con muchos docentes a la cabeza, sindicatos, equipos de gestión, universidades y diversos actores, han trabajado fuertemente y dado una lucha silenciosa que no ha terminado contra la mirada Eurocéntrica del saber y el conocimiento. Esta lucha prolongada a lo largo de la historia continua, y no es fácil salir, romper e incluso manifestarse contra un sistema sesgado de reproducción y conocimiento que nada tiene que ver con nuestra realidad. Comenzar a pensarnos desde nuestras realidades, conformar y restablecer nuestra propia historia, educar en el sentido de poder proporcionar garantías y nuevos desafíos que incluyan, sobre todo como menciona Dussel(2014) “... la vida es lo que hay que preservar, la vida humana cualitativamente hasta su felicidad..."

El otro punto es poder comprender y tomar lo mejor de la experiencia, es no descuidar a la Educación, y no alimentar la Mercantilización de la Educación, desprestigiando a la Educación Pública y sus instituciones, facilitando a los sectores financieros y especuladores que intentan desde hace mucho tiempo apoderarse de lo más importante que tiene un pueblo, la riqueza de su formación. Como hace varios años lo viene haciendo la OMC (Organización Mundial del Comercio) en diversos países interviniendo en sus decisiones y ofreciendo un mercado competitivo en aquellas naciones que no tienen una política educativa fuerte.

"LA PANDEMIA ESTÁ EN NOSOTROS", no sé, si despertó el sentido de culpa esperado quizá por ese hombre, si fue un comentario al azar al ver la realidad y quizá seguramente el también hizo su análisis antes de decir esa frase, o solo la soltó y listo esperando algún tipo de 
reacción, o simplemente las ganas de conversar con alguien producto del encierro y escupió eso. Verdaderamente despertó otras cosas en mí, un sentido y una valoración de algunos temas que no tenía pensado analizar ni mucho menos, si considero que la pandemia no está en nosotros, que hay mucho para hacer y cambiar seguramente mejorar, individual y socialmente, y que podemos comenzar ahora, proponiendo y ejecutando ideas.

\section{Bibliografía}

DUSSEL, Enrique. En Aguer Bárbara (editora); Cartografía del Poder y la Descolonialidad. CABA, del Signo, 2014. 